\title{
Taxonomic Review of the Genus Euodynerus (Hymenoptera: Vespidae: Eumeninae) in the Korean Peninsula
}

\author{
Jeong-Kyu Kim* \\ Department of Biological Sciences, Faculty of Science, Hanseo University, Seosan 356-706, Korea
}

\begin{abstract}
Korean species of the genus Euodynerus Dalla Torre were taxonomically reviewed. Four species were confirmed: E. trilobus, E. dantici violaceipennis, E. nipanicus nipanicus, and E. quadrifasciatus atripes. The specimens previously identified as $E$. dantici brachyotomus and $E$. notatus pubescence form North Korea were re-examined, and corrected to E. dantici violaceipennis and E. nipanicus nipanicus, respectively. Euodynerus quadrifasciatus atripes was re-described for future researchers. After careful reading previous descriptions, Euodynerus seuli Radoszkowski was tentatively supposed to be conspecific with E. nipanicus.
\end{abstract}

Keywords: Euodynerus, taxonomy, misidentification, redescription, Korean Peninsula

\section{INTRODUCTION}

The members of the genus Euodynerus Dalla Torre are the dominant appearing eumenine wasps in semi-natural areas of Korea (Kim et al., 2005). Though six species have been identified from the Korean Peninsula to date (Kim and Yoon, 1996), their taxonomy was very fragmentary and somewhat disorganized in several species. North Korean fauna have been established with only four specimens (Giordani Soika, 1976, 1982). The South Korean fauna also have not been thoroughly studied. Specifically, a previously recorded species of E. notatus pubescens was questionable with regards to the occurrence in the Korea Peninsula (Giordani Soika, 1986), and the taxonomic identity of Rhynchium seulii Radoszkowski which was placed as a member of Euodynerus by van der Vecht and Fischer (1972) has yet to be revealed. In the present study, North Korean Euodynerus specimens treated by Giordani Soika $(1976,1982)$ were examined, and misidentification was corrected. The original description of Euodynerus quadrifasciata atripes based on one female from North Korea by Giordani Soika (1976) was so brief that its taxonomic adoption for Far Eastern material remained tentative (Yamane, 1990). To elucidate the taxonomic identity of Rhynchium seulii Radoszkowski, its original description and additional records were carefully checked.
As a result, four species in the Korean Peninsula were identified, including E. trilobus, Euodynerus dantici violaceipennis, E. nipanicus nipanicus, and E. quadrifasciatus atripes. The key to the four species were given together with digital images. The species identified as E. dantici brachytomus and E. notatus pubescens in North Korea proved to have been a misidentification of Euodynerus dantici violaceipennis and E. nipanicus nipanicus, respectively. For future researchers, re-description of E. quadrifasciatus atripes was provided. A very poorly known Korean species, Rhynchium seuli Radoszkowski, was tentatively supposed to be conspecific with E. nipanicus nipanicus.

\section{MATERIALS AND METHODS}

Specimens which were housed at the Hanseo University (Seosan-si, Chungcheongnam-do, Korea) and Sk. Yamane Collection (Kagoshima Univ., Japan) were mainly used in this study. North Korean material was loaned from the Hungarian Natural History Museum (HNHM). All the examined specimens other than those from the Korean Peninsula were also listed herein.

Terminology principally follows that of Bohart and Stange (1965), Carpenter and Cumming (1985) and Yamane (1990). (c) This is an Open Access article distributed under the terms of the Creative Commons Attribution Non-Commercial License (http://creativecommons.org/ licenses/by-nc/3.0/) which permits unrestricted non-commercial use, distribution, and reproduction in any medium, provided the original work is properly cited.

pISSN 2234-6953 eISSN 2234-8190
*To whom correspondence should be addressed

Tel: 82-41-660-1349, Fax: 82-41-688-3403

E-mail: kwasp@hanseo.ac.kr 
All measurements were taken as the maximal length of body parts being measured under an image analyzer. Body length was measured from the anterior margin of the head to the posterior margin of the metasomal tergum II. Lateral lobes were excluded from the measurement of the clypeal width.

As to previously described species and subspecies, the reference to the original publication is provided, with depository of types in parenthesis following. The synonymic list includes the references treating the forms that occur in the Korean Peninsula.

\section{SYSTEMATIC ACCOUNTS}

\author{
Order Hymenoptera \\ Family Vespidae \\ Subfamily Eumeninae \\ Genus Euodynerus Dalla Torre, 1904
}

Euodynerus Dalla Torre, 1904: 38, name for Odynerus, subgenus Leionotus, III ${ }^{\mathrm{e}}$ Division, Sect. II, Saussure, 1853; van der Vecht and Fischer, 1972: 87; Carpenter, 1986: 70; van der Vecht and Carpenter, 1990: 23. Type species: Vespa dantici Rossi, designated by Blüthgen, 1938.

Diagnosis. Out of the eumenine genera having sessile metasoma (metasomal segment I almost as broad as segment II, and tergum I much broader than long), this genus can be easily separated by the combination of the following external features. Cephalic fovea medium-sized to large, shallow and transverse, posteriorly bordered by a weak carina (sometimes obsolete) and with a pair of pits usually spaced by the diameter of posterior ocellus. Pretegula carina and furrow well developed. Epicnemial carina usually well developed; pleural and epipleural sutures deep and wide with sharp dense keels on the bottom. Posterior margin of horizontal face of metanotum carinate and dentate; posterior face of metanotum almost precipitous. Propodeum without shelf; submedian carina ending near each posterolateral area of metanotum (the superior median portion of propodeum without carina), where the carina usually strongly developed into an acute projection. Metasomal tergum I without basal transverse carina, with an apical lamella at the same plane as tergal disk. Sternum II somewhat truncated behind its basal sulcus. Prestigma of forewing short, less than one-third as long as stigma. Terminal segment of male antenna bent backward.

\section{Key to the Korean species of the genus Euodynerus Dalla Torre}

1. Ocellar region polished with distinct three tubercles: one of them, apically bifid, situated just behind anterior ocel- lus and the others close to inner margins of posterior ocelli (circular region of Fig. 1A, B). Upper frons just below ocellar region distinctly and densely bipunctate, with both large punctures and medium-sized punctures (Fig. 1B). Cephalic fovea comparatively small, its breadth almost as long as the distance between posterior ocelli (Fig. 1A). In both sexes, yellow apical band on tergum I being dilated in lateral parts and black median part characteristically arrow head-shaped (Fig. 2A). …... E. trilobus (Fabricius)

- Ocellar region without any tubercle (Fig. 1C). Upper frons strongly reticulate or densely punctate mainly with large punctures, not distinctly bipunctate, at most interspace among punctures with sparse small punctures. Cephalic fovea comparatively larger, its breadth longer than the distance between posterior ocelli (Fig. 1C, J, O). In both sexes, the apical band on tergum I simple or dilated laterally (Fig. 2A-D); if being dilated in lateral parts, black median part not arrow head-shape (Fig. 2B). ….................... 2

2. Clypeus longer than broad in both sexes; female clypeus with dense longitudinal carinae and its apical margin almost truncated (Fig. 1D, E). In both sexes, below twothird of posterior vertical face of metanotum impunctate and shining; posterior margin of horizontal face of metanotum with large irregular denticles; carina on propodeal posterior face strong (Fig. 1F). Mesonotum almost bare at most partially with sparse short hairs (Fig. 1G). Cephalic fovea medially smooth and somewhat polished (Fig. 1C). Body maculation extensive: apical band on tergum I being dilated laterally (Fig. 2B).

E. dantici violaceipennis Giordani Soika

- Clypeus as long as broad, or broader than long in both sexes; female clypeus with dense punctures (not carinate) and its apical margin shallowly to moderately emarginated (Fig. 1H, I, M, O). In both sexes, posterior vertical face of metanotum below shagreened, not shining; posterior margin of horizontal face of metanotum with fine and somewhat regular denticles (Fig. 1K). Mesonotum with dense erect hairs (Fig. 1J, P). Cephalic fovea somewhat coarse with dense various size punctures. Body maculation reduced: apical band on tergum I narrow and simple without distinct lateral dilation (Fig. 2C-E). …................ 3

3 . Head and mesosoma with short erect dense hairs of uniform length (Fig. 1J). Clypeus almost as long as broad(Fig. $1 \mathrm{H}, \mathrm{I})$. Cephalic fovea with both large punctures in its marginal portion, which are almost as large as nearby punctures, and microscopic punctures. Metasomal tergum II with a short but distinct apical lamella; punctures on the tergum strong and large (Fig. 1L). Sternum II medially with a longitudinal groove in subbasal part.

E. nipanicus nipanicus (Schulthess)

- Head and mesosoma with long disheveled hairs of vari- 

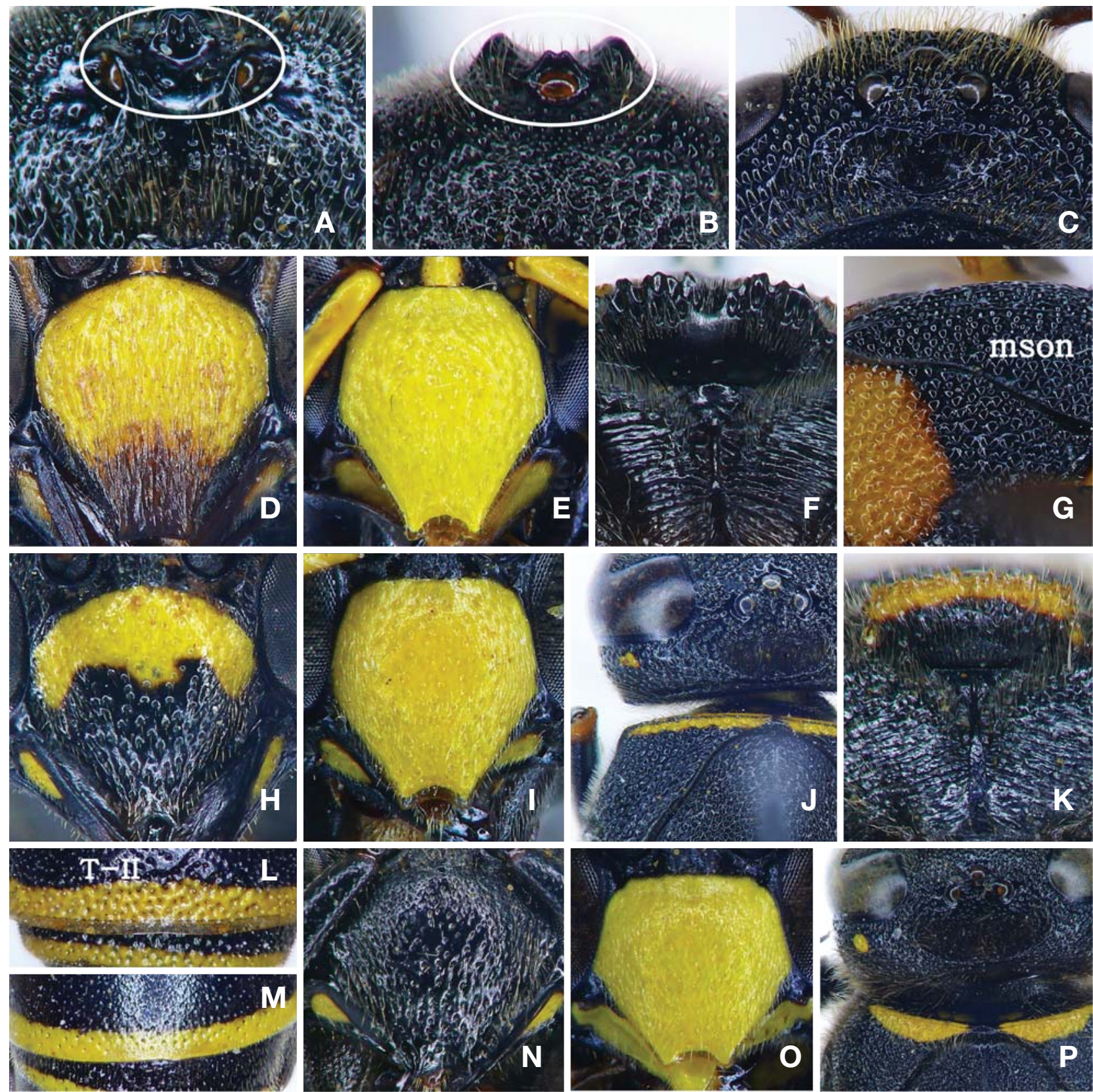

Fig. 1. Euodynerus trilobus (A, B), E. dantici violaceipennis (C-G), E. nipanicus ( $\mathrm{H}-\mathrm{L})$ and E. quadrifasciatus atripes (M-P). A, Tubercles in ocellar region, dorsal view; B, Tubercles in ocellar region, frontal view; C, Head, dorsal view; D, Clypeus, female; E, Clypeus, male; F, Posterior vertical face of metanotum and posterior propodeal face; G, Mesosoma and pronotum, lateral view showing almost bare face; H, Clypeus, femalw; I, Clypeus, male; J, Head and mesosoma (mson) showing short erect dense hairs; $\mathrm{K}$, Posterior vertical face of metanotum and posterior propodeal face; L, Metasomal tergum II (T-II) with apical lamella; M, Tergum II without apical lamella; N, Clypeus, female; O, Clypeus, male; P, Head and mesosoma showing long disheveled dense hairs.

able length (Fig. 1P). Clypeus broader than long (Fig. 1N, $\mathrm{O})$. Cephalic fovea mainly with dense micropunctures on almost entire face. Metasomal tergum II without apical lamella; punctures on the tergum feeble and smaller (Fig. 1M). Sternum II medially without a distinct longitudinal groove in subbasal part, at most with an obscure impression. ……...... E. quadrifasciatus atripes Giordani Soika

\section{Euodynerus trilobus (Fabricius), 1787}

Vespa triloba Fabricius, 1787: 290, China (coll. Lund). 
Rhynchium trilobus Fabricius: Kim, 1970: 552, Pl. 52, fig. 633.

Euodynerus trilobus (Fabricius): Kim and Yoon, 1996: 202.

Material examined. Korea: 1 우, Isl. Jejudo, Hanrim, 8 Oct 1955, collector not stated; 1 ð , Isl. Jejudo, 31 Aug 1957, Lee BJ; 1 ऽ, Mt. Hanra, collection date and collector not stated. Japan: 10 우 우 and 36 이 $^{7}$ (recorded in Yamane, 1990).

Distribution. Africa to China: Jiangsu, Zhejiang; Korea: Isl. Jejudo; Japan: Honshu, Shikoku, Kyushu; Taiwan.

Remarks. As shown in the key, this species is unique in having three tubercles in ocellar region. In Korea, this species is very rare and known just from Isl. Jejudo. There has been no find of additional specimens since 1958.

Euodynerus dantici violaceipennis Giordani Soika, 1973 Euodynerus dantici violaceipennis Giordani Soika, 1973: 114, 우, Canton, China (coll. Giordani Soika, Venezia, Italy); Giordani Soika, 1986: 134-135; Yamane, 1990: 50-51; Kim and Yoon, 1996: 202.

Euodynerus dantici brachytomus (Kostylev): Giordani Soika, 1982: 40, misidentification; Giordani Soika, 1986: 133; Kim and Yoon, 1996: 202.

Odynerus dantici Rossi: Yasumatsu, 1950: 1455; Ishikawa, 1965: 297; Kim, 1970: 550, Pl. 51, fig. 628; Kim, 1980: 109.

Material examined. Korea: $47 \sigma^{\nearrow} \sigma^{\nearrow}, 10$ 우 우, Gyeongsangnam-do: Mt. Gayasan, 5 Aug 1960, Kim CW; 1 ð, Seoul: Ui-dong, 6 Jun 1961, Kwon YH; 1 우, Chungcheongnam-do: Hongseong, 19 Aug 1961, Park JS; $1 \sigma^{7}$, Jeollanam-do: Haenam, Mt. Duryunsan, 15 Aug 1972, Kim JI; 1 우, Gangwondo: Gangchon, 23 Jun 1974, Yang DH; 1 ㄲ, 2 우 우, Jeollanam-do, Seungju, Mt. Jogyesan, Seonamsa (temp.), 7 Aug 1976, Nam SH; 2 우 우, ditto. 8 Aug 1976, Kim CW; 1 우, Gyeongsangnam-do: Jungsan-ri, Mt. Jirisan, 30 Jul 1981, Han HY; 1 우, Seoul: Seocho-gu, Mt. Cheonggyesan, 6 Sep 1986, Kim KH; 1 우, ditto, 15 Aug 1991, Park MR; 1 우, Prov. South Pyeongyang: Lyong-ak san, 14 km W. of Pyeongyang, 30 Jul 1975 (specimen identified E. dantici brachytomus by Giordani Soika, 1982); 1 우, Gyeonggi-do: Mt. Myeongjisan, 23 Aug 1978, Han HY; 1 ð, Yangpyeong-gun, Yeonsu-ri, 31 Aug 1980, Jang KS; 1 우, Mt. Chukryeongsan, Sudong, 28 Sep 1980, Jang KS; 1 우, ditto, 11 Jul 1983, Hong HS; 1 우, Gwangju-gun, Eommi-ri, 18 Sep 1981, Kim YR; 1 우, Gyeongsangbuk-do: Gyeongsan-si, Yeungnam Univ. campus, 17 Aug 1987, Choi WH; 1 우, Gyeongsangnam-do: Milyanggun, Chodong-myeon, Sanwol-ri, Deoksansa, 8 Aug 1987, collector not stated; 1 우, Gyeonggi-do: Ganghwa-gun, Isl. Buleumdo, 18 Aug 1987, Yu HJ; 1 우, Gangwon-do: Myeongju-gun, Seongsan, 13 Aug 1989, Kim D; 1 ऽ, Gyeongsang- nam-do: Haman-gun, Baekjin-myeon, Baekunam, 11 Jun 1990, collector not stated; 1 우, Gyeonggi-do: Namyangjugun, 25 Aug 1991, Yun GY; $2 \sigma^{\nearrow} \sigma^{\nearrow}$, Isl. Ganghwado, Hamheodongcheon, 7 Aug 1992, Kim JK; 1 우, $2 \sigma^{7} \sigma^{7}$, Chungcheongnam-do: Taean-gun, Nam-myeon, Dalsan-ri, 2 Aug

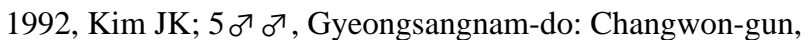
Gusan-myeon, Gubok-ri, 10 Aug 1992, Kim JK. Japan:

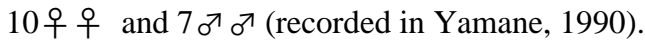

Distribution. China: Jianxi (Canton, Soochow); Russian Far East; Korea; Japan: Honshu, Awaji-shima, Kyushu.

Remarks. This species is polytypic, comprising more than ten subspecies in the Palearctic region (van der Vecht and Fischer, 1972; Giordani Soika, 1986), and three subspecies has been known to distribute in the Far East, i.e., subsp. brachytomus, subsp. violaceipennis, and subsp. nigrescens of which key was provided by Yamane (1990). In addition to Yamane's conception for subspecies separation, following differences might be useful for their separation. Body markings of subsp. brachytomus are orange yellow and very extensive, for example covering almost entire face of tergum I except for narrow median longitudinal line and larger part of pronotal dorsum. However, body markings of subsp. violaceipennis, and subsp. nigrescens are deep yellow, yellow or bright yellow, and larger median part of tergum I black and at most anterior half of pronotal dorsum marked. As far as what is known so far, three subspecies are geographically segregated as follows: subsp. brachytomus is known to distribute in Transbaikal, near Mongolian area and North Korea, while subsp. violaceipennis in the Far East (Russian Far east, North east China, South Korea, and Japan), and subsp. nigrescens in Central and Southern Ryukyus of Japan. The sole North Korean specimen identified as E. dantici brachytomus, which extended the distributional range to North Korea eastward, by Giordani Soika (1982) is well matched with the South Korean material herein except for slightly deeper maculation (but still not orange yellow, and some of the old Korean specimens were also deep yellow). Thus this subspecies is no longer the Far Eastern and Korean element.

\section{Euodynerus nipanicus nipanicus (Schulthess), 1908}

Lionotus tomentosus var. nipanicus Schulthess, 1908: 287288.

Euodynerus notatus pubescens (Thompson): Giordani Soika, 1976: 291; Kurzenko, 1995: 306; Kim and Yoon, 1996: 202.

Euodynerus niponicus (Schulthess): Giordani Soika, 1982: 41.

Euodynerus nipanicus (Schulthess): Giordani Soika, 1986: 138; Kim and Yoon, 1996: 202.

? Rhynchium seuli Radoszkowski, 1890: 231, ð, Seoul, Korea (Mus. Berlin); Dalla Torre, 1894: 48; 1904: 35; Oka- 
moto, 1924: 202, 230.

? Euodynerus seuli Radoszkowski: van der Vecht and Fischer, 1972: 100-101; Kim and Yoon, 1996: 202.

Material examined. Russia: $1 \sigma^{\top}$, Peishla, nr. Ussurisk Reserve (150 m alt.), S. Primorie, 22 Jul 1990, Yamane S; $2 \sigma^{\nearrow}$ ఠ, $17 \mathrm{~km} \mathrm{S.W}$. of Krounovka (130-150 m alt.) nr. Chinese border, S. Primorie, 29 Jul 1990, Yamane S. Korea: $1 \sigma^{\Im 7}$, Seoul, 21 Jul 1971, Kim JI; $1 \Im^{7}$, Prov. South Pyeongyang: Dae-Sangsan, 12 km of Pyeongyang, 21 May 1970 (specimen identified E. notatus pubescens by Giordani Soika, 1976); $1 \sigma^{\nearrow}$, Seoul: Gwanak-gu, Bongcheon-dong, 23 Aug 1986, An JS; 1 ð, Yongsan-gu, Huam-dong, 31 May 1987, Kim HK; 1 ð , Dobong-gu, Sinchang-dong, 1 Sep 1987, Park K; 1 ð7, Seongbuk-gu, Donam-dong, 19 May 1988, Lee YK; 1 우, Eunpyeong-gu, Nokbeon-dong, 26 Jun 1988, Jeong JH; 1 우, Mt. Cheonggyesan, 26 Jun 1988, JJI; 1 우, Eunpyeong-gu, Eungam-dong, 17 Jul 1992, Lee GI; 1 우, Eunpyeong-gu, Mt. Bukhansan, 8 Sep 1992, Kim SY; $1 \sigma^{7}$, Yangcheon-gu, Sinjeong-dong, 17 May 1997, Yeo SH; 1 우, Mt. Wangbangsan, 15 Jun 1975, Ko SS; 1 우, Mt. Surak, 9 Jun 1977, Lee IS; 1 ð ditto, 27 May 1986, Lee HC; 1 우, Gyeonggi-do: Bokwangsa, 19 Apr 1978, Kim JH; 1 우, Mt. Chukryeongsan, Sudong, 12 Aug 1980, Kim JI; 1 우, Mt. Cheonmasan, 26 May 1984, collector not stated; $2 \sigma^{\top} \sigma^{7}$, Kyomun-ri, 29 May 1986, Lee $\mathrm{HC} ; 1$ 우, Yeoncheon-gun, Baekhak-myeon, Gorangpo-ri, 13 Aug 1987, Kim JI; 1 우, Incheon-si, Seo-gu, Seogot, 1 Sep 1989, An HJ; 1 우, Gwangleung, 22 Sep 1990, Noh SA; 1 우, Bukhansanseong, 28 May 1991, Kim YA; 1 우, Goyang-gun, Mt. Bukhansan, 19 Aug 1991, Yun SJ; 1 우, Dongducheon, Songnae-ri, 27 Aug 1991, Yun SA; 1 『 , ditto, 1 Sep 1991, Yun SA; 1 우, Gangwon-do: Gangchon, Chunseong-gun, 18 Jun 1983, Jang KS; 1 우, Pyeongchang-gun, Doam-myeon, Yonsan-ri, 29 Jun 1985; 1 우, Pyeongchang, Daehwa, Baekildo, 16 Jul 1985, Sin KH; 1 우, Chungcheongnam-do: Gongju-si, Okryong-dong, Gongsanseong, 15 Aug 1988, Mun K; 1 ऽ, Taean-gun, Nam-myeon, Dalsan-ri, 3 Aug 1992, Kim JK; 1 우, Chungcheongbuk-do: Chungju-si, Mt. Namsan, 28 Aug 2000, Kim JK; 1 우, Gyeongsangbuk-do: Kyeongsan, Youngnam Univ. campus, 12 May 1987, Ki JS; $1 \sigma^{\nearrow}$, ditto, 30 May 1987, Kim DB; 1 우, 1 ㄲ, ditto, 8 May 1989, Lee JW; 1 우, ditto, 5 Aug 1989, Lee JW; 1 ð', ditto, 9 May 1990, Bae KH; 1 우, 1 శ , ditto, 24 Jun 1990, Lee JH; 1 જ , ditto, 26 May 1990, Baek UK; 1 ð , ditto, 28 May 1990, Cho JR; 1 우, ditto, 1 Jun 1990, Kim MJ; 1 우, Cheongdo, Unmunsa, 24 Aug 1988, Kim JK; 2 우 우, Jeollabuk-do: Buan-gun, Naebyeonsan, 26 Jun 1991, Son YH, Ko KM. Japan: 33 우 우 and 90 ठ

Distribution. China (Lee, 1985; Giordani Soika, 1986): Heilongjian, Jilin, Liaoning, Hebei, Shandong ("Tai-shan"), Zhejiang (Hanchaw, Ning-Po, Chusan), Jiangsu (Nan king,
Shanghai), Guangdong, Guangxi, Yunnan, Sichuan (Yachow, Suifu, Tsianfou); Eastern Russia: Magadan, Sakhalin, Amur, Primorie; the Korean Peninsula; Japan: Hokkaido, Honshu, Iwai-jima, Isl. Oki (Nishino-shima), Shikoku, Kyushu, Isl. Tsushima, Isl. Amakusa, Akune-oshima, Isl. Osumi, Isl. Ogasawara (introduced?).

Remarks. Based on the European voucher specimens (우, Steiermark, Röcksec, NE Mureck, 46 ${ }^{\circ} 43^{\prime}: 15^{\circ} 48^{\prime}$, 20 Jul 1998, Gusenleitner J; 우, Steiermark, Wardprecht, S Stranden, $46^{\circ} 47^{\prime}: 15^{\circ} 48^{\prime}$, 19 Jul 1991, J. Gusenleitner; ðフ, Steiermark,

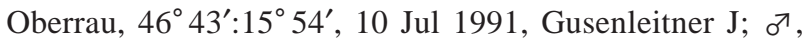
ditto, 15 Aug 1993, ditto), Euodynerus notatus has no apical lamella on tergum II as in E. quadrifasciata, which is easily observable characteristic to separate this species from $E$. $n i$ panicus. Considering the short erect dense hairs on head and mesosoma, strong punctures and the different shape of cephalic fovea (Cephalic fovea of $E$. notatus with large dense punctures laterally and microscopic punctures medially, but $E$. quadrifascitus with dense microscopic punctures almost throughout the face), E. notatus and E. quadrifasciatus are also separated valid species. The sole North Korean specimen identified as Euodynerus notatus pubescens by Giordani Soika (1976) is a mere misidentification of E. nipanicus, and it is highly possible that Far Eastern material previously identified as E. notatus might be E. nipanicus. This species is also polytypic, and the other two subspecies, i.e., subsp. flavicornis and subsp. ryukyuensis, are more extensively maculated and distributed in Ryukyus of Japan (refer to Yamane, 1990).

The original description of Rhynchium seuli is insufficient for species distinction, and available information on this species is scarce, with only additional reports by Okamoto (1924). Although Kim $(1970,1980)$ also described this species from Korea, his voucher specimens ( $\sigma^{\top}$, Korea, Isl. Wando, 23 Aug 1961, Park KJ; 우, Korea, Aengmubong, 8 May 1971, [HYEU 12a]) were Ancistrocerus oviventris. The described minor external features and color pattern in the original description and Okamoto's work are most similar to those for E. nipanicus nipanicus. According Dr. Koch (personal communication), the holotype of this species was not in Mus. Berlin in which other types and Korean material treated by Radoszkowski (1890) were housed. Until direct examination of type material, my present treatment on the possible synonymy of this species under the name of E. nipanicus nipanicus herein should remain tentative.

\section{Euodynerus quadrifasciatus atripes Giordani Soika, 1976}

Euodynerus quadrifasciatus atripes Giordani Soika, 1976: 292, 우, Prov. Ryang-gang, Plateau Chann-Pay, Samziyeon, 1,500 m (HNHM); Yamane and Tano, 1987: 341; 


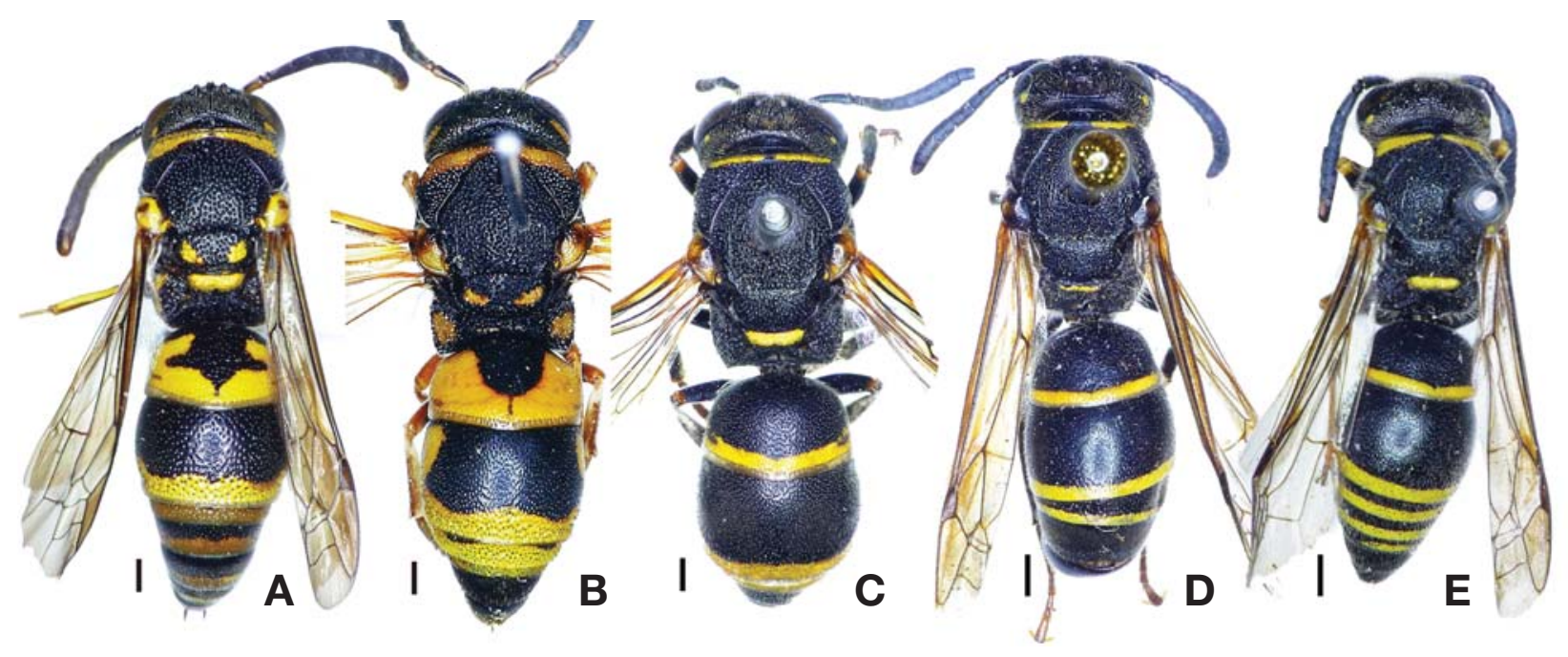

Fig. 2. General habitus. A, Euodynerus trilobus, male; B, E. dantici violaceipennis, female; C, E. nipanicus, female; D, E. quadrifasciatus atripes, female, holotype; E, E. quadrifasciatus atripes, male. Scale bars $=1 \mathrm{~mm}$.

Yamane, 1990: 47 (in key), 59; Kim and Yoon, 1996: 202. Rhynchium quadrifasciatus Fabricius: Kim, 1970: 551-552.

Material examined. Russia: 4 우 우, $10^{7}, 40 \mathrm{~km}$ E. of Ussurisk, Ussurisk Reserve (140-160 m alt.), S. Primorie, 14 Jul 1990, Yamane S; $1 \delta^{7}, 17$ km S.W. of Krounovka (130-150 $\mathrm{m}$ alt.) nr. Chinese border, S. Primorie, 29 Jul 1990, Yamane S. Korea: 1 우, Prov. Ryang-gang: Plateau Chann-Pay, Samziyeon, 1,500 m (holotype); 1 우, Seoul: Mt. Cheonggyesan, 26 Jun 1985, Song KI; 1 우, Mt. Bukhansan, 18 May 1986, SJH; 1 우, 1 ð , Gyeonggi-do: Mt. Suraksan, 14 May 1978, Jeong HJ, Kang SJ; 1 ð , Maseok, 26 May 1989, Cho HS; $2 \sigma^{\nearrow}$ 『 , Pocheon, Mt. Jugeumsan, 31 May 1992, Kim JK; 1 ð, Gangwon-do: Naeseolak, Yongdae-ri, 28 May 1983, Kim JI; 1 우, Pyeongchang, Gapyeong, 5 Jun 1985, Lee OK; 1 우, Pyeongchang, Doam, Yongam-ri, 9 Jun 1985, Kim YS; 1 우, Chungcheongnam-do: Cheongyang-gun, Mt. Chilgapsan, 26 May 1990, Park EH; 1 우, Gangwon-do: Gapyeong-gun, Mt. Cheonggyesan, 11 Jun 1991, Kim DJ; $1 \sigma^{\top}$, Jeollabuk-do: Geumreung-gun, Eopo-myeon, Yongdae-ri, 28 May 1992, Kim JK; $1 \sigma^{7}$, Gangwon-do: Wonju-si, Socho-myeon, Kyohak 2-ri, 6 Jun 1996, Yin HS; 1 우, Seoul: Mt. Guryongsan, 27 May 1998, Park HC. Japan: 1 우 and $2 \sigma^{\nearrow}$ ð (recorded in Yamane, 1990).

Redescription. Female. Body length 8.5-10.0 mm. Cephalic fovea broadly transverse (its breadth $1.5 \times$ as long as the distance between posterior ocelli), with dense micropunctures, thus distinctly demarcated from surrounding area with macropunctures, with a slightly deeper area in its medial portion. Clypeus more or less distinctly broader than long, approximately 1.2 times as broad as long. Epicnemial carina very weak, and almost obscure in upper half of ventral mesepisternum. Body sculpture coarse, and body punctures shallow and medium in size.

Following parts/markings yellow (Fig. 2D): a transverse lower frontal spot, a triangular marking at madibular base, a pair of spots on temples, a narrow anterior band on pronotal dorsum (interrupted medially), horizontal face and upper marginal portion of vertical face of metanotum, narrow and somewhat regular apical bands on terga I-V (all the bands almost identical in width), and posterior lateral parts of sternum II. Lower faces of all tarsi reddish black.

Males much as in females except for following differences. Body length $6.0-7.5 \mathrm{~mm}$. Clypeus only slightly broader than long. In addition to the markings mentioned for the female, the following parts yellowish (Fig. 2E): entire surface of clypeus, labrum and mandible except for margins, antennal scape below, both anterior and posterior spots on tegula, a short apical band on tergum $\mathrm{V}$, a line on inner face of fore femur in its half, inner face of mid femur, and outer faces of all tibiae and tarsi. Inner faces of all tarsi reddish yellow.

Distribution. Far Eastern Russia: Primorie; the Korean Peninsula; Japan: C. and N. Honshu.

\section{ACKNOWLEDGMENTS}

I would like to express my cordial thanks to Dr. Csösz Sànor (Curator of Hymenoptera Collection of HNHM) and Dr. Josef Gusenleitner (Linz, Austria) for their preparation of North Korean specimens and European specimens, and to Professor Seiki Yamane (Kagoshima University, Japan) for allowance 
of examination of his specimens during my visiting study in Japan.

\section{REFERENCES}

Bohart RM, Stange LA, 1965. A revision of the genus Zethus Fabricius in the western hemisphere (Hymenoptera: Eumenidae). University of California Publications in Entomology, 40:1-208.

Carpenter JM, 1986. A synonymic generic checklist of the Eumeninae (Hymenoptera: Vespidae). Psyche, 93:61-90.

Carpenter JM, Cumming JM, 1985. A character analysis of the North American potter wasps (Hymenoptera: Vespidae: Eumeninae). Journal of Natural History, 19:877-916.

Dalla Torre KW, 1894. Catalogus Hymenopterum. Vol. 9. Vespidae (Diploptera). Engelmann, Leipzig, pp. 1-81.

Dalla Torre KW, 1904. Hymenoptera, Fam. Vespidae. Genera Insectorum, 19:1-108.

Fabricius IC, 1787. Mantissa insectorum, sistens eorum species nuper detectas adiectis characteribus genericis, differentiis specificis, emendationibus, observationbus. Ioh. Christ. Fabricii. Impensis C. G. Proft, Hafniae, pp. 1-348.

Giordani Soika A, 1973. Notulae vespidologicae XXXV. Descrizione di nuovi Eumenidi. Bolletino del Museo Civico di Storia Naturale di Venezia 24:97-131.

Giordani Soika A, 1976. Vespidi ed eumenidi raccolti in Corea (Hymenoptera). Annales Historico-Naturales Musei Nationalis Hungarici, 68:287-293.

Giordani Soika A, 1982. Vespidi ed eumenidi raccolti in Corea (Hymenoptera) 2. Folia Entomologica Hungarica, 43:39-41.

Giordani Soika A, 1986. Eumenidi palearctici nuovi o poco noti. Bolletino del Museo Civico di Storia Naturale di Venezia, 35:91-162.

Ishikawa R, 1965. Vespidae. In: Iconographia Insectorum Japonicorum. Colore Naturali Edita. Vol. 3 (Eds., Asahina S, Ishihara T, Yasumatsu K). Hokuryukan, Tokyo, pp. 291-297.

Kim CW, 1970. Illustrated encyclopedia of fauna and flora of Korea. Vol. 11. Insecta (III). Samhwasa, Seoul, pp. 1-891.

Kim CW, 1980. Distribution atlas of insects of Korea. Series 3. Hymenoptera and Diptera. Korea University Press, Seoul, pp. 1-356.

Kim JG, Choi YC, Choi JY, Kim SE, Kim KY, Kim JK, Lee JE, 2005. Environmental evaluation by using Hymenoptera induced by Bamboo Pipe Traps indicated by Eumenid Wasp (Hymenoptera: Eumenidae). Korean Journal of Applied Entomology, 44:307-315.

Kim JK, Yoon IB, 1996. Synonymic list and distribution of Eumenidae (Hymenoptera) in Korean Peninsular. Entomological Research Bulletin (KEI) Supplement:197-208.

Kurzenko NV, 1995. Family Vespidae. In: Key to the insect of Russian Far East, Vol. VI. Neuroptera, Mecoptera, Hymenoptera. Part 1 (Ed., Lehr PR). Nauka, St. Petersberg, pp. 264-324.

Lee TS, 1985. Economic insect fauna of China, Fasc. 30, Hymenoptera: Vespoidea. Science Press, Beijing, pp. 1-159.

Okamoto H, 1924. The insect fauna of Querlpart Island. Bulletine of the Agricultural Experiment Station, GovernmentGeneral of Chosen, 1:47-233.

Radoszkowski O, 1890. Hymenoptera de Koreé. Horae Society of Entomology of Ross, 24:229-232.

Schulthess A, 1908. Neue Eumeniden aus Japan (Hymenoptera). Mittwilungen der Schweizerischen Entomologischen Gesellschaft, 11:284-288.

van der Vecht J, Carpenter JM, 1990. A catalogue of the genera of the Vespidae (Hymenoptera). Zoologische Verhandelingen, 260:1-62.

van der Vecht J, Fischer FCJ, 1972. Palaearctic Eumenidae. Hymenopterum Catalogus (nova editio), 8:1-199.

Yamane SK, 1990. A revision of the Japanese Eumenidae (Hymenoptera: Vespoidea). Insecta Matsumurana (New Series), 43:1-189.

Yamane SK, Tano T, 1987. Studies on Japanese Eumenidae (Hymenoptera: Vespoidea). Transactions of the Shikoku Entomological Society, 18:327-345.

Yasumatsu K, 1950. Family Vespidae. In: Iconographia Insectorum Japonicorum (Ed., Esaki T). Hokuryukan, Tokyo, pp. 1453-1457. 